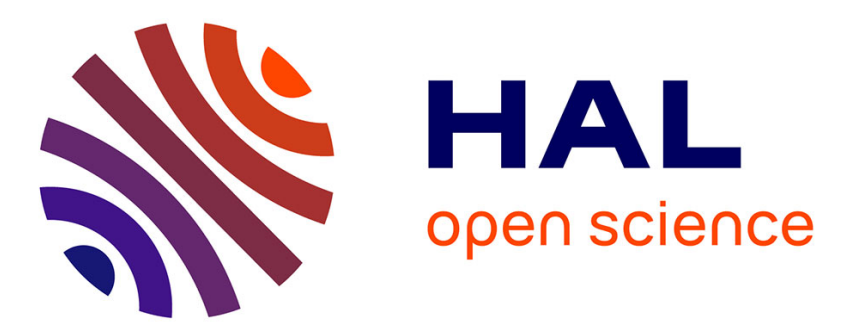

\title{
At the boundary between anthropogenic and environmental systems: the neglected emissions of indirect nitrous oxide
}

\author{
Arnaud Helias
}

\section{- To cite this version:}

Arnaud Helias. At the boundary between anthropogenic and environmental systems: the neglected emissions of indirect nitrous oxide. International Journal of Life Cycle Assessment, 2019, 24 (3), pp.412-418. 10.1007/s11367-018-1564-3 . hal-02622801

\section{HAL Id: hal-02622801 https://hal.inrae.fr/hal-02622801}

Submitted on 26 May 2020

HAL is a multi-disciplinary open access archive for the deposit and dissemination of scientific research documents, whether they are published or not. The documents may come from teaching and research institutions in France or abroad, or from public or private research centers.
L'archive ouverte pluridisciplinaire HAL, est destinée au dépôt et à la diffusion de documents scientifiques de niveau recherche, publiés ou non, émanant des établissements d'enseignement et de recherche français ou étrangers, des laboratoires publics ou privés. 
1 At the boundary between anthropogenic and environmental systems: the neglected emissions of indirect nitrous oxide.

2Elsa, Research group for Environmental Lifecycle and Sustainability Assessment, 34060, Montpellier, France;

$7 \quad$ 3Sustainable Engineering, Technische Universität Berlin, Berlin, Germany.

8 Corresponding author: Arnaud Hélias

9 Address : Montpellier SupAgro, 2 place Pierre Viala, 34060 Montpellier Cedex 1, France

10 E-mail: arnaud.helias@supagro.fr; Phone : +334 996127 65; FAX : no fax number

\section{1. Introduction}

12 Nitrous oxide $\left(\mathrm{N}_{2} \mathrm{O}\right)$ is the third most important Greenhouse Gas (GHG) after carbon

13 dioxide and methane. Its emissions must be quantified and even more so for agricultural 14 activities, which are the main human interventions in the global nitrogen cycle. This paper focuses on how Life Cycle Assessment (LCA) deals with this gas. It discusses what is included in the inventory of activities and what is included in the impact assessment and shows the inconsistency of modelling between agricultural and non-agricultural activities.

To address this topic, it is necessary to begin by presenting the general structure of the assessment. The availability of a simple carbon footprint measurement has become one

21 of the key tools for stakeholders to develop awareness of climate change issues. Due to the complexity of the mechanisms relating human activities and climate change, the 23 modelling strategy can be planned in two steps: first, the "carbon footprint 24 practitioners" model anthropogenic activities in order to determine GHG emissions and second, the "climate scientists" model global warming mechanisms in order to provide 
the Global Warming Potential (GWP). On one hand, GHG emissions result from human activities and need to be assessed for each studied alternative or system. On the other hand, GWPs are global, independent from the activities and only change according to science updates, with International Panel for Climate Change (IPCC) assessment report editions. In other words, carbon footprints are the results of GHG $\times$ GWP. Only GHGs vary according to the anthropogenic systems whereas GWPs remain constant for the practitioners, providing the environmental system is assumed to be stable from one study to another.

This understanding of the carbon footprint matches with the LCA framework in which the system is divided into two steps: First, the Life Cycle Inventory (LCI) describes emissions from techno-economic activities (anthropogenic system) towards the soil, water and air compartments (the environmental system). Second, the Life Cycle Impact Assessment (LCIA) converts elementary flows into impacts and damages using Characterization Factors (CFs). LCA practitioners perform LCA by producing the LCI and by using CFs from LCIA (LCA $=\mathrm{LCI} \times \mathrm{CFs}$ ) while the LCIA scientists provide CFs by modelling the causal fluxes into the environment.

This partitioning is useful, and seems both obvious and simple. LCA practitioners assess the environmental issues of products and services without exhaustive knowledge and ad hoc modelling of environmental mechanisms. For the interpretation of results, it is mandatory to understand the general structure and the main hypotheses of LCIA methods. However, when an LCA is executed, the environmental modelling task is 47 simplified by using CFs within the LCA software.

48 Nonetheless, this partitioning can also be uncertain; although the limit between LCI and LCIA is most often obvious, sometimes a sequence of steps can occur, making it difficult to define the boundary between them. This has previously been discussed for pesticides 
51 (Rosenbaum et al. 2015) and spatial and temporal limits have thus been proposed (van

52 Zelm et al. 2014). Weidema et al. (2017) provide the outline of the delimitation between

53 LCI and LCIA and they suggest how this dichotomy could be overcome. In the present

54 paper, the significance of $\mathrm{N}_{2} \mathrm{O}$ emissions and their place in LCA are discussed.

\section{Methods}

\subsection{Direct and indirect $\mathrm{N}_{2} \mathrm{O}$ emissions}

$\mathrm{N}_{2} \mathrm{O}$ releases are thoroughly addressed in the agricultural section of the IPCC report (De Klein et al. 2006), differentiating between direct and indirect nitrous oxide emissions (in the LCA community, the latter are sometimes called induced emissions while the "indirect" term is rather employed for background emissions). Direct emissions merge few atmospheric $\mathrm{N}_{2} \mathrm{O}$ releases, with air emissions resulting in $\mathrm{N}$ that enters managed (agricultural) soil. Indirect emissions result from re-deposition after volatilization and leaching/runoff of other $\mathrm{N}$ compounds, essentially ammonia $\left(\mathrm{NH}_{3}\right), \mathrm{NOx}$ and nitrate $\left(\mathrm{NO}_{3}{ }^{-}\right)$. These induce secondary emission flows.

Fig. 1 describes the impact pathway, linking $\mathrm{N}$ emissions from human activities to global warming. This illustrates the relationships between anthropogenic and environmental systems. The involved mechanisms include:

1. Direct $\mathrm{N}_{2} \mathrm{O}$ releases. These emissions are obviously driven by the anthropogenic system, which is determined by technological or functioning choices. This flow has to be quantified in the LCI.

2. Other direct N-compound emissions. They also have to be quantified in the LCI.

3. Emissions of $\mathrm{N}_{2} \mathrm{O}$ and other $\mathrm{N}$-compounds after $\mathrm{N}$ incorporation into the soil, considered as direct. These emissions depend upon the spreading quantity and their nature (chemical composition), however they are also driven by the 
environmental system, such as pedoclimate conditions, rainfall or atmospheric temperature. These aspects constitute pieces of information for spreading management. They are highly specific and have to be adapted to each condition. Direct emissions are part of the practitioner's task and contribute to LCI work. From this standpoint, agricultural soil is considered as a part of the technosphere (i.e. part of the production system).

4. Mechanisms for re-deposition of other $\mathrm{N}$-compounds and/or for their biological conversion to $\mathrm{N}_{2} \mathrm{O}$. These mechanisms are unrelated to the product described. employed for determining direct $\mathrm{N}_{2} \mathrm{O}$ emissions (flows 1,2 and 3 to $\mathrm{N}_{2} \mathrm{O}$ in Fig 1 ). Models originate from various sources: IPCC tier 1, country level factors, or site-specific data. Concerning the releases of other $\mathrm{N}$-compounds (flows 3 to $\mathrm{NH}_{3}, \mathrm{NO}_{\mathrm{x}}$ and $\mathrm{NO}_{3}{ }^{-}$in

Insert Figure 1 about here

\subsection{Modelling of $\mathrm{N}_{2} \mathrm{O}$ emissions}

Covering the different carbon footprints and emission factor databases, models are Fig. 1), many approaches are used such as direct measurements, site-specific models or 
100 international guidelines like IPCC tier 1 or other similar sources for ammonia (2016)

101 and nitrates (Roy et al. 2003).

102 For indirect emissions (flow 4), LCAs (and carbon footprints) only use one model,

103 described in the tier 1 IPCC guidelines: this involves $1 \%$ of volatilized and $0.75 \%$ of

104 leached N-compounds. All works use the same conversion factors in the LCI to represent 105 this environmental mechanism of re-deposition and/or biological conversion, which are 106 not influenced by the technical system. This is well documented for agricultural sectors, 107 which are the main contributors of $\mathrm{N}_{2} \mathrm{O}$ emissions. Practitioners commonly calculate 108 direct and indirect emissions for agricultural products but this raises an issue for non109 agricultural sectors.

113 IPCC guidelines, Chapter 11 , stipulate that "the sources of $\mathrm{N}$ as $\mathrm{NH}_{3}$ and $\mathrm{NO}_{\mathrm{x}}$ are not 114 confined to agricultural fertilisers and manures, but also include fossil fuel combustion, 115 biomass burning, and processes in the chemical industry" (De Klein et al. 2006). 116 Moreover, in Chapter 7 they specify that "it is good practice to estimate and report $\mathrm{N}_{2} \mathrm{O}$ 117 emissions from atmospheric deposition of $\mathrm{NO}_{\mathrm{x}}$ and $\mathrm{NH}_{3}$ where a country already has an 118 inventory of these gases" (Gillenwater et al. 2006).

119 These considerations have been quoted in a national emissions report guideline where 120 "Parties may report, as a memo item, indirect $\mathrm{N}_{2} \mathrm{O}$ emissions from other than the 121 agriculture and LULUCF [Land use, land-use change, and forestry] sources. These 122 estimates of indirect $\mathrm{N}_{2} \mathrm{O}$ should not be included in national totals. For Parties that 123 decide to report indirect $\mathrm{CO}_{2}$, the national totals shall be presented with and without 124 indirect $\mathrm{CO}_{2} . "$ (UNFCCC 2014). 
125 This points to a compromise between theoretical (non-agricultural indirect $\mathrm{N}_{2} \mathrm{O}$ 126 emissions should be reported), and operational assessments (these indirect emissions

127 are often non-assessable and generally low). They are neglected to allow comparisons to 128 be made with a same perimeter for all parties: both direct and indirect emissions are 129 used for agricultural activities, while other activities only involve direct emissions.

\subsubsection{Product carbon footprint and LCA studies}

131 The carbon footprints of products are estimated in the same way as for countries. 132 Ammonia emissions from industries or nitrates from wastewater treatment plants do 133 not lead to any consequence on climate change, while crop production and animal waste 134 spreading do have effects. Indirect $\mathrm{N}_{2} \mathrm{O}$ emissions do not result from $\mathrm{NO}_{\mathrm{x}}$ from 135 combustion, while they are a product of $\mathrm{N}$ field fertilisation. Since it is not mandatory in 136 the current guidelines, carbon footprint practitioners do not deal with these non137 agricultural emissions (some are probably quantified but this remains an exception).

138 This differs for LCA practitioners because N-compounds lead to other impacts. 139 Regarding the latest recommendation for the European product environmental footprint 140 (Fazio et al. 2018), $\mathrm{NH}_{3}, \mathrm{NO}_{3}{ }^{-}$and $\mathrm{NO}_{\mathrm{x}}$ are involved in marine and terrestrial 141 eutrophication, $\mathrm{NH}_{3}$ and $\mathrm{NO}_{\mathrm{x}}$ in acidification and particulate matter, and $\mathrm{NO}_{\mathrm{x}}$ in 142 photochemical ozone formation. Emissions of these substances are quantified in LCI for 143 all activity sectors. They lead to these impacts through the characterization factors of 144 LCIA methods. Through this inventory work for other impacts, it is possible to quantify 145 indirect $\mathrm{N}_{2} \mathrm{O}$ emissions for all activity sectors.

\subsection{Quantification of indirect $\mathrm{N}_{2} \mathrm{O}$ emissions for non-agricultural sectors}

147 This quantification is performed by providing CFs to represent the indirect $\mathrm{N}_{2} \mathrm{O}$ 148 emissions. They are applied to the datasets in the ecoinvent 3.4 database (Wernet et al. 2016), with an "at point of substitution" system model. These CFs are obviously not used 
with the agricultural datasets as the mechanism has already been taken into account at

151 LCI level.

152 The CFs to assess GWP of $\mathrm{N}$-compounds through indirect $\mathrm{N}_{2} \mathrm{O}$ emissions are calculated

153 from their $\mathrm{N}$-content, the re-deposition (1\%) and leaching (0.75\%) of indirect emission

154 factors according to the emission compartment, and the IPCC2013 $\mathrm{N}_{2} \mathrm{O} \mathrm{GWP}_{100 y}(265$

$155 \mathrm{~kg}_{\mathrm{CO} 2 \mathrm{eq}} / \mathrm{kg}_{\mathrm{N} 2 \mathrm{O}}$ ); see Table 1 . In addition to $\mathrm{NH}_{3}, \mathrm{NO}_{3^{-}}$and $\mathrm{NO}_{\mathrm{x}}$, the closely related 156 chemical forms $\left(\mathrm{NH}_{4}{ }^{+}, \mathrm{NO}_{2}{ }^{-}, \mathrm{NO}\right)$ and unspecific emissions (nitrogen, and organic bound 157 nitrogen) are also taken into account.

Insert Table 1 about here

159

160

161

162

163

164

165

166

167

168

169

170 $171 \quad 100 \%$ (this latter group contains the 334 processes without conventional climate

172 change impact but with N-compounds). If each ecoinvent entry is considered separatly,

\section{Results}

Firstly, the CFs in Table 1 are used for assessing the climate change impacts of each unitary dataset (i.e. unit process). This implies the impact of its elementary flows, without determining the process tree and the impact associated to its technology inputs. Out of the 14927 datasets of the ecoinvent 3.4 database, 9070 do not involve global warming effects nor N-compound elementary flows. These include market processes without any elementary flows but only technical ones.

The variation of climate change impacts for the remaining 5857 is illustrated in Figure 2. In these sets, 1907 show no change in impact. For these datasets, which are agricultural or do not contain any $\mathrm{N}$ compounds (387), ecoinvent already computes the indirect effect in the LCI. $67 \%$ remain, that show a variation; for $19 \%$ of processes, the increase is greater than $5 \%$; for $16 \%$ it is greater than $10 \%$ and for $7 \%$, greater than 
173 indirect $\mathrm{N}_{2} \mathrm{O}$ emissions from $\mathrm{N}$-compounds cannot be neglected for the non-agricultural 174 sectors. Indeed, the relative variation is too high.

Figure 3 illustrates the result with cumulative datasets (with the impact of the whole process tree) where the lack of indirect emissions is less of an issue. Over all the ecoinvent 3.4 datasets, 219 do not have global warming effects, nor N-compound 180 elementary flows. Over the remaining 14708 datasets, the impacts change for almost all 181 of them (99\%) although they remain mostly small. For only $11 \%$, the increase exceeds $1 \%$, while for just 157 datasets (1\%), the increase is greater than $5 \%$. Nevertheless for this small fraction of datasets, climate change due to N-compounds cannot be neglected. Data from Figure 2 and 3 are available in the supplementary materials section of this article.

\section{Discussion and conclusion}

\subsection{Current situation: inconsistency between LCI and LCIA}

There is a noteworthy LCI/LCIA dichotomy in LCA. On one hand, for LCI, the result is

"the quantitative description of flows of matter, energy, and pollutants that cross the system boundary"(Jolliet et al. 2016). On the other hand, for LCIA, "impact pathways consist of linked environmental processes, and they express the causal chain of

193 subsequent effects originating from an emission or extraction."(Jolliet et al. 2004).

194 Continuity across the border between these two types of result is essential.

195 The current climate change impact assessment results from its history, evolving from 196 the first GWP values at the beginning of the nineties to present-day guidelines and 
pathways. This implies that the environmental system (the LCIA) starts with the

198 radiative forcing of GHG. To ensure continuity, the environmentally driven indirect $\mathrm{N}_{2} \mathrm{O}$

199 emissions should be described in the anthropogenic system (the LCI), however for sakes

200 of simplicity, this is only done for the agricultural sector.

201 The final result depicts an inconsistency between LCI and LCIA for the non-agricultural

202 sectors. Fortunately, for most of the studies, these missing emissions do not represent a

203 strong contribution to climate change, but they do matter in some cases. It is more of an

204 issue at unit process levels.

205 4.2. Proposal of a new boundary

206 The representation of environmental mechanisms in LCI is supported by an

207 environmental context affecting human decisions (and associated emissions) or a 208 specific situation which cannot be represented through a simple CF1. Nonetheless, this is

209 not true for re-deposition of $\mathrm{N}$-containing compounds and/or biological conversion to $210 \mathrm{~N}_{2} \mathrm{O}$. These mechanisms do not contribute to the assessment of initial emissions. All 211 practitioners use the same representation provided by IPCC.

212 The system border between LCI and LCIA should be movable and this should be easy to 213 achieve. The indirect emissions from N-Compounds (flow 4 in Fig. 1) would be included 214 in the LCIA by using the CFs listed in Table 1 and the indirect emissions would then be 215 removed from agricultural datasets. That can be easily automated to update a database 216 like ecoinvent.

1 This will be less and less tenable with spatialized and temporalized CFs, which are progressing for many kinds of impact, as has been done for water since several years. 
217 In the case where a practitioner does not agree with the IPCC indirect emission factors,

218 he could investigate further into these mechanisms and propose improved CFs. These

219 latter values would then be available to all practitioners. Representing redeposit and

220 leaching in the LCIA would make it possible to introduce spatial considerations through

221 regionalized CFs, involving more complex mechanisms such as atmospheric circulation,

222 soil properties and soil cover (see for example Bühlmann et al. (2015) for the latter).

223 Regionalized CFs would also allow for the consideration of country-level guidelines.

224 With this pragmatic boundary, by assigning the anthropogenic system to LCI and the 225 environmental system to LCIA, direct emissions (flows 1 and 2 for non-agricultural 226 activities, and flow 3 for agricultural spreading activities in Figure 1) remain in the LCI. 227 This is obvious for 1 and 2 which are only driven by human activities. Flow 3 results 228 from both systems: a spreading operation decided by a farmer, partially based on 229 environmental considerations. To represents this specificity, flow 3 has to remain in LCI. 230 However in the latter case, a default model of emissions subsequent to soil $\mathrm{N}$-input 231 could be used to determine CFs when LCA practitioners do not have access to extensive 232 information on spreading conditions. This has been done for marine eutrophication in 233 the 2008 Recipe version (Goedkoop et al. 2013). For this, CFs were available for 234 elementary flows of "fertilizer, applied (N-component)" and "manure, applied (N 235 component)" (names are those used in Simapro software) to represent volatilization 236 and leaching mechanisms, and for the rest of the impact causal chain. This has not been 237 done elsewhere and is not included in the 2016 Recipe version anymore, as N-limited 238 eutrophication is no longer assessed. 
240 From a technical point of view, the new LCI/LCIA boundary does not raise any

241 difficulties, but global warming is the most assessed impact in LCA and concerns a much

242 broader scope: a change in the way it is addressed should be considered with caution.

243 With indirect $\mathrm{N}_{2} \mathrm{O}$ emissions in LCIA, the N-compounds involved come up as "new" 244 GHGs, in addition to the IPCC list. This should therefore be accompanied by the 245 necessary explanations, showing the consistency between these new factors and the 246 mechanisms previously described by the IPCC. It will also be necessary to explain that 247 ignoring indirect emissions for non-agricultural sectors can no longer be justified, since 248 precursors must be quantified for other impacts. Any change in the way global warming 249 is assessed cannot be made without significant communication efforts.

250 Changing the LCI/LCIA boundary requires ensuring consistency between LCI-level work 251 and LCIA uses. For the agricultural sector, LCIs with indirect $\mathrm{N}_{2} \mathrm{O}$ emissions (old LCIs 252 that are not updated or new datasets but defined as previously) must not be assessed 253 with the new CFs to avoid double counting. The opposite situation is also true. New LCIs 254 (without redeposit and leaching/runoff) must not be associated with current LCIA 255 method, to avoid neglecting indirect emissions.

256 Since agricultural LCA-practitioners are aware of indirect $\mathrm{N}_{2} \mathrm{O}$ emissions, these kind of 257 issues should not be too prevalent. Nevertheless, if the definition of a new LCI/LCIA 258 boundary allows a better articulation between these two steps, it remains for 259 practitioners to ensure the consistency of the modelling.

$260 \quad$ 4.4. Alternative and concluding remarks

261 An alternative is to keep indirect N20 emissions at the LCI level and add them for non262 agricultural datasets in the LCI databases. This could also be easily automated by 
263 database providers, by adding a part of N-compound emissions (determined by IPCC

264 indirect emission factors) to direct $\mathrm{N}_{2} \mathrm{O}$ emissions.

265 In this scenario, no change is required at the LCIA level and the LCI/LCIA boundary is 266 not modified. It is easy to set up. However, two points must be raised: (1) LCA 267 practitioners modelling new non-agricultural inventories must change their habits to 268 take into account the indirect emission of $\mathrm{N}_{2} \mathrm{O}$, which could be a challenge. (2) The 269 environmental mechanisms of indirect emissions remain at the LCI level, which does not

270 fit to the implicit separation of anthropological and environmental systems in the 271 LCI/LCIA framework. That means that future improvements in environmental 272 mechanism modelling, with spatialized re-deposition and more accurate re-emission 273 models, will have to be implemented by practitioners and the LCI databases updated. A 274 new LCI/LCIA boundary seems more relevant: systems with human intervention in LCI 275 and environmental systems without human involvement in LCIA.

276 More generally, impact pathways related to nitrogen compounds should be harmonised, 277 as they involve the same redeposit mechanisms as for climate change, terrestrial 278 acidification and eutrophication. The same model and identical boundaries with LCI 279 should be used in the LCIA methods.

280 CFs are increasingly accurate regarding environmental mechanisms. The quality and 281 quantity of inventory datasets are also improving rapidly. It is therefore crucial to 282 ensure a consistency between the two LCA mainstays.

\section{5. Acknowledgments}

284 The author thanks his colleagues A. Benoist, C. Bessou, L. Lardon and P. Roux for the 285 fruitful discussions that led to this article. He is grateful to the ecoinvent Centre for 
providing the unit version of the database. Anonymous reviewer is warmly thanked for

287 his valuable comments that helped improving this paper.

288

289

290

291

292

293

294

295

296

297

298

299

300

301

302

303

304

305

306

307

308

309

\section{References}

Bühlmann T, Hiltbrunner E, Körner C, et al (2015) Induction of indirect $\mathrm{N}_{2} \mathrm{O}$ and NO emissions by atmospheric nitrogen deposition in (semi-)natural ecosystems in Switzerland. Atmos Environ 103:94-101. doi: 10.1016/j.atmosenv.2014.12.037

De Klein C, Novoa RSA, Ogle S, et al (2006) Chapter 11. N20 Emissions From Managed Soils, and CO2 Emissions From Lime and Urea application. In: 2006 IPCC Guidelines for National Greenhouse Gas Inventories. p 11.1-11.54

Fazio S, Castellani V, Sala S, et al (2018) Supporting information to the characterisation factors of recommended EF Life Cycle Impact Assessment method. EUR 28888 EN, European Commission, JRC109369, Ispra

Gillenwater M, Saarinen K, Ajavon A-LN (2006) Chapter 7. Precursors and Indirect Emissions. In: 2006 IPCC Guidelines for National Greenhouse Gas Inventories. p 7.17.16

Goedkoop M, Heijungs R, Huijbregts M, et al (2013) ReCiPe 2008 - First edition (revised) - Report I: Characterisation. The Hague, Netherland

Jolliet O, Müller-Wenk R, Bare J, et al (2004) The LCIA midpoint-damage framework of the UNEP/SETAC life cycle initiative. Int J Life Cycle Assess 9:394-404. doi: 10.1065/lca2004.09.175

Jolliet O, Saadé-Sbeih M, Shaked S, et al (2016) Environmental Life Cycle Assessment. Taylor \& Francis

Rosenbaum RK, Anton A, Bengoa X, et al (2015) The Glasgow consensus on the delineation between pesticide emission inventory and impact assessment for LCA. 
311 Roy RN, Misra RV, Lesschen JP, Smaling EM (2003) Assessment of soil nutrient balance.

$312 \quad$ FAO Fertil plant Nutr Bull 14:101p

313 UNFCCC (2014) Report of the Conference of the Parties on its nineteenth session; held in 314 Warsaw from 11 to 23 November 2013; Addendum; Part two: Action taken by the 315 Conference of the Parties at its nineteenth session FCCC/CP/2013/10/Add.3

316 van Zelm R, Larrey-Lassalle P, Roux P (2014) Bridging the gap between life cycle 317 inventory and impact assessment for toxicological assessments of pesticides used in crop production. Chemosphere $100: 175-181$.

doi: 10.1016/j.chemosphere.2013.11.037

320 Weidema BP, Schmidt J, Fantke P, Pauliuk S (2018) On the boundary between economy and environment in life cycle assessment. Int J Life Cycle Assess 23:1839-1846. doi: $10.1007 / \mathrm{s} 11367-017-1398-4$

Wernet G, Bauer C, Steubing B, et al (2016) The ecoinvent database version 3 (part I): overview and methodology. Int J Life Cycle Assess 21:1218-1230. doi: $10.1007 / \mathrm{s} 11367-016-1087-8$

(2016) EMEP/EEA air pollutant emission inventory guidebook 2016 - Technical guidance to prepare national emission inventories. European Environment Agency, Luxembourg 
Table 1. Characterization factors of $\mathrm{N}$-compounds

\begin{tabular}{|c|c|c|c|c|}
\hline N-Compound ${ }^{1}$ & $\begin{array}{c}\text { N-content } \\
(\%)\end{array}$ & $\begin{array}{c}\text { Emission } \\
\text { compartment }\end{array}$ & $\begin{array}{c}\text { Indirect } \\
\text { emission } \\
\text { factor (\%) }\end{array}$ & $\begin{array}{c}\text { CF } \\
\left(\mathrm{kg}_{\text {co2eq }} / \mathrm{kg}\right)\end{array}$ \\
\hline Ammonia $\left(\mathrm{NH}_{3}\right)$ & $82 \%$ & air & $1 \%$ & 2.18 \\
\hline Ammonium carbonate $\left(\left(\mathrm{NH}_{4}\right)_{2} \mathrm{CO}_{3}\right)$ & $29 \%$ & air & $1 \%$ & 0.77 \\
\hline Ammonium, ion $\left(\mathrm{NH}_{4}^{+}\right)$ & $78 \%$ & water & $0.75 \%$ & 1.54 \\
\hline Nitrate $\left(\mathrm{NO}_{3}^{-}\right)$ & $23 \%$ & air & $1 \%$ & 0.60 \\
\hline Nitrate $\left(\mathrm{NO}_{3}^{-}\right)$ & $23 \%$ & soil, water & $0.75 \%$ & 0.45 \\
\hline Nitric oxide (NO) & $47 \%$ & air & $1 \%$ & 1.24 \\
\hline Nitrite $\left(\mathrm{NO}_{2}^{-}\right)$ & $30 \%$ & water & $0.75 \%$ & 0.61 \\
\hline Nitrogen $(\mathrm{N})$ & $100 \%$ & air & $1 \%$ & 2.65 \\
\hline Nitrogen $(\mathrm{N})$ & $100 \%$ & soil & $0.75 \%$ & 1.99 \\
\hline Nitrogen oxides $\left(\mathrm{NO}_{\mathrm{x}}\right)$ & $30 \%{ }^{2}$ & air & $1 \%$ & 0.81 \\
\hline Nitrogen, organic bound (N) & $100 \%$ & water & $0.75 \%$ & 1.99 \\
\hline
\end{tabular}

$332 \quad{ }^{1}$ Ecoinvent elementary flow names.

$333{ }^{2}$ Assuming a molar mass of $\mathrm{NO}_{\mathrm{x}}$ equals to $\mathrm{NO}_{2}$. 


\section{Figure captions}

337 Figure 1. Schematic of the pathways involved in $\mathrm{N}_{2} \mathrm{O}$ release. 1-3: direct emissions, 4:

338 indirect emissions, 5: impact assessment. See text for details.

339 Figure 2. Relative increase of climate change impacts of unitary datasets by taking into 340 account indirect $\mathrm{N}_{2} \mathrm{O}$ emissions for all activity sectors.

341 Figure 3. Relative increase of climate change impacts of cumulative datasets by the 342 consideration of indirect $\mathrm{N}_{2} \mathrm{O}$ emissions for all activity sectors.

343

344 


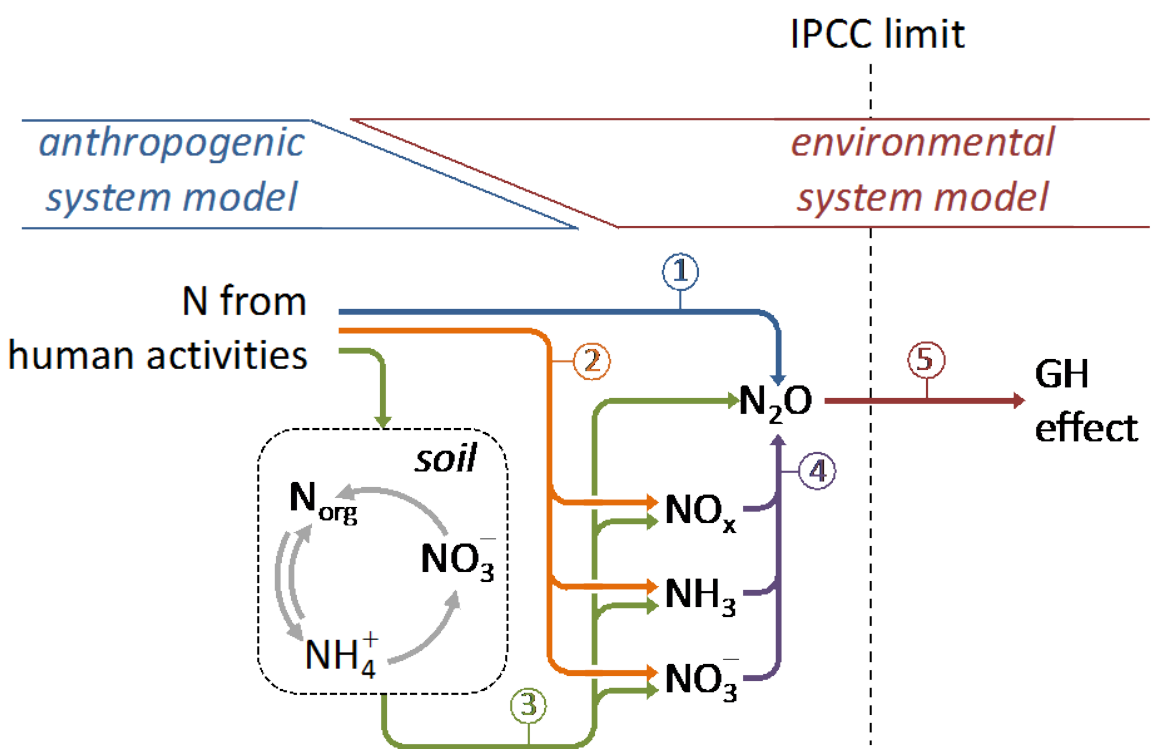


Figure 2

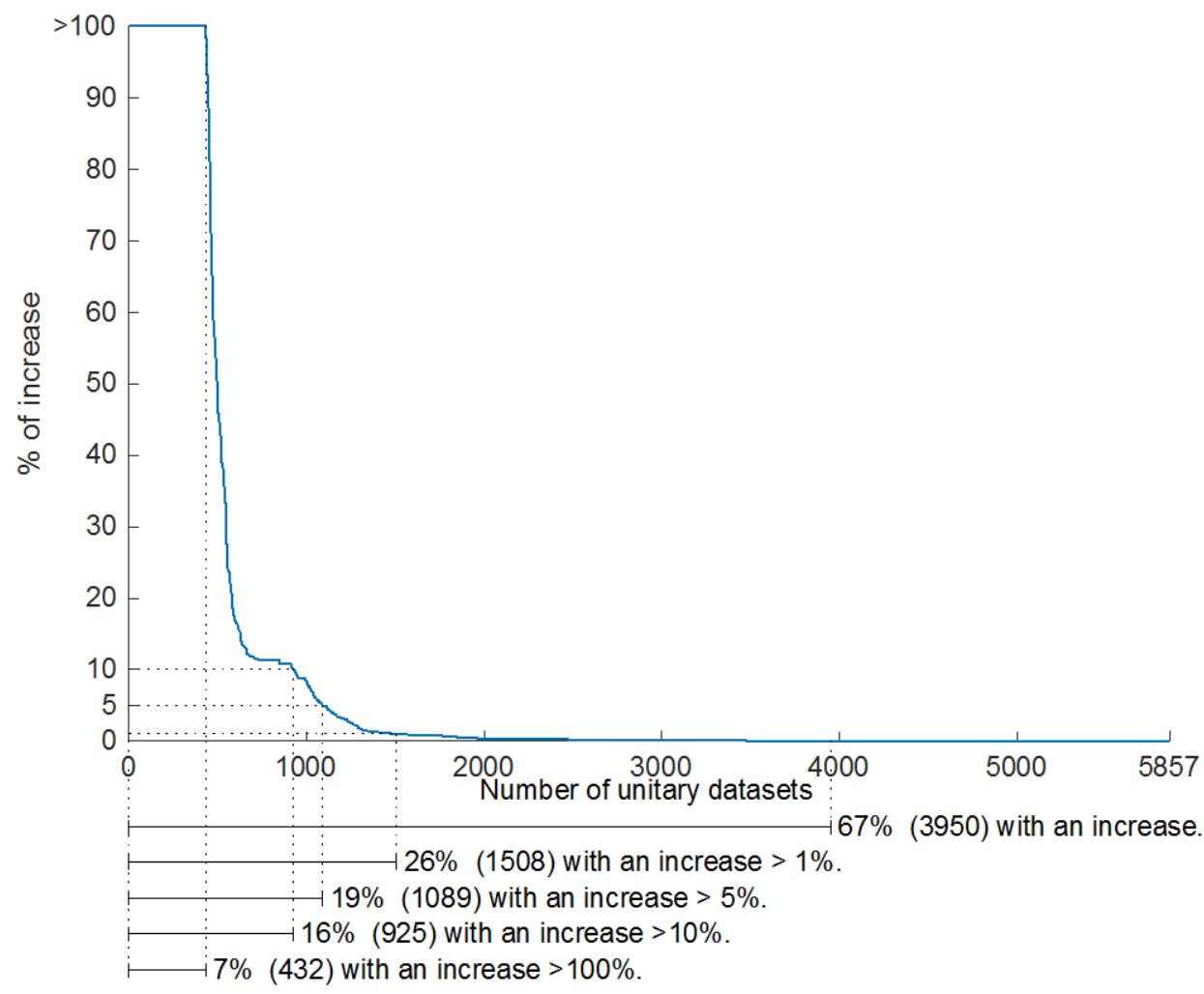


$351 \quad$ Figure 3

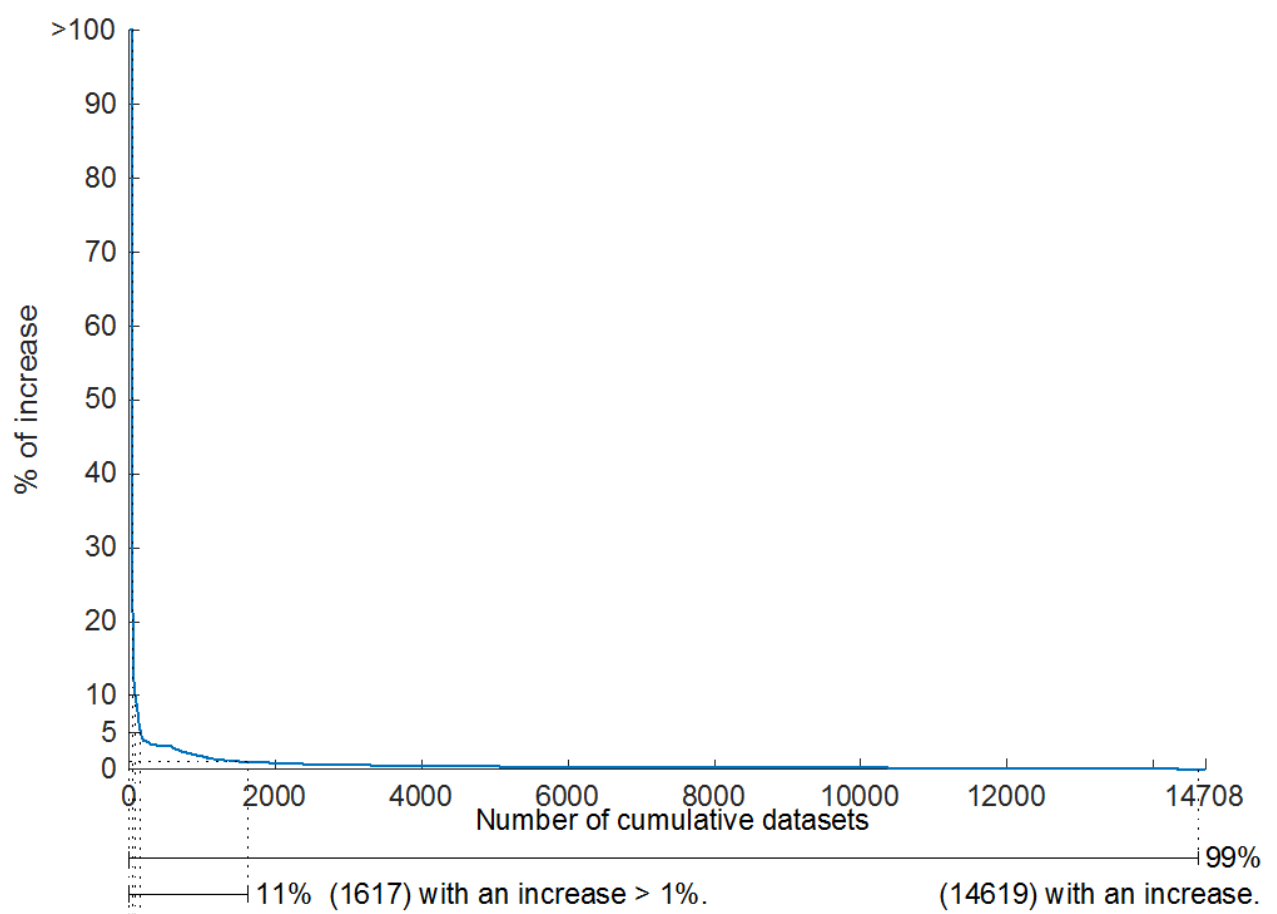

$1 \%$ (157) with an increase $>5 \%$.

$1 \%$ (82) with an increase $>10 \%$.

$\ddot{0} 0 \%$ (41) with an increase $>100 \%$. 